\title{
THE RELATIONSHIPS OF ASSERTIVENESS AND RESPONSIVENESS TO SEXUAL BEHAVIOR
}

\author{
Kyungok SIM ${ }^{1)}$ and Woo Young CHUN ${ }^{2}$ \\ ${ }^{1)}$ Kyungsung University, South Korea \\ ${ }^{2)}$ Chungnam National University, South Korea
}

\begin{abstract}
Personality traits that influence on individuals' communication and relationship behavior, assertiveness and responsiveness, are presumed to be important components for sexual behavior. We investigated the relationships of assertiveness and responsiveness to sexual behavior and tested the relative contributions of personality and physical traits (e.g., body shapes, fluctuating asymmetry, and digit ratios) to the prediction of sexual behavior. Additionally, we examined whether the effect of these personality traits on sexual behavior interacts with each other and with body attractiveness. Assertiveness had substantial effects on sexual behaviors for both sexes, whereas responsiveness had a negative effect in men and null effect in women. The finding of the relative contributions of personality and physical traits indicate that variation in sexual behavior is much bigger for personality traits than physical traits, probably gaining insight into the magnitude of variation in traits under frequency-dependent selection and those under positive selection. Moreover, interaction effects indicate that mating success is also an outcome of the concerted interplay of personalities and body attractiveness. Findings support the evolutionary hypotheses that personality traits are alternative adaptive strategies evolved as a means of ensuring fitness.
\end{abstract}

Key words: assertiveness, responsiveness, body attractiveness, fluctuating asymmetry, 2D:4D, sexual behavior

\section{INTRODUCTION}

Personality traits combined to influence individuals' communication and relationship behaviors are presumed to be important components for romantic relationship initiation and mating success, which are fitness-enhancing characteristics. Two of these components are assertiveness and responsiveness, which are generalized classifications of individuals' communication styles and other social behavioral patterns, reflecting the ways that people express their thoughts and needs and initiate social interaction (Alberti \& Emmons, 1995; Anderson \& Martin, 1995; Richmond \& McCroskey, 1990; Twenge, 2001). Evolutionary psychologists hypothesize that personality differences are the psychological mechanisms evolved to solve recurrent adaptive problems associated with fitness, and such mechanisms are flexibly operated in response to individual and environmental factors (Barrett \& Kurzban, 2006; Buss, 1991; Tooby \& Cosmides, 1992). Moreover, empirical findings suggest the possible existence of common evolutionary pressure on personality traits linked

Correspondence concerning this article should be addressed to Kyungok Sim, A Libral Arts Education, Kyungsung University, 309 Suyoung-ro, Namgu, Busan/48434, South Korea (e-mail: simkyungok@yahoo. com). 
to communication and social interaction patterns and sexual behavior (Buss \& Greiling, 1999; Gangestad \& Simpson, 1990; Sakaguchi, Sakai, Ueda, \& Hasegawa, 2007). If personality traits are under sexual selection then those traits should be associated with individual differences in sexual behavior.

Therefore, the current study investigated the relationship of assertiveness and responsiveness to sexual behavior and the relative importance of each personality component. We also examined whether the effect of these personality traits on sexual behavior interacts with each other and with body attractiveness. Although there are a large number of studies showing that personality and physical traits (i.e., body shapes, fluctuating asymmetry, and digit ratios) play an important role in sexual behavior (Alvergne, Jokela, \& Lummaa, 2010; Nettle, 2005), no study has investigated the relative contributions of personality and physical traits to sexual behavior. Thus, we tested the relative importance of personality and physical traits in predicting sexual behavior.

Assertiveness is a set of personality traits including elements of dominant, assertive, aggressive, competitive, defends own beliefs, acts as a leader, and so forth (Richmond \& McCroskey, 1990; Twenge, 2001). It is considered to be a subtrait of extraversion and a key part of the masculine gender role and overlapped with a main component of selfmonitoring, which refers to interpersonal communication skills, with expressive selfrepresentation in high self-monitors (Sakaguchi et al., 2007; Twenge, 2001). Highly assertive individuals clearly express their own thoughts and opinions, act in their own best interests, and stand up for their right without intrusion of others' (Alberti \& Emmons, 1995; Richmond \& McCroskey, 1992; Thompson, Ishii, \& Klopf, 1990; Twenge, 2001). They are also better at the interpersonal communication and relationship and feel competent and self-assured (Alberti \& Emmons, 1995; Kearns \& Calhoun, 2010). Hence assertiveness may facilitate access to mates and increase chances of mating. Specifically, action-oriented characteristics and sociality (e.g., willingness to take a stand and dominance) and the willingness to face new challenges may prompt individuals to actively initiate sexual expression and seek out an available mate (Hromatko, Tadinac, \& Vranic, 2008; Troutman, Burke, \& Beeler, 2000).

This possibility has received indirect support from studies finding the association between the characteristics of assertiveness and psychological traits linked to mate access. For example, more assertive individuals exhibit higher sexual motivation and preoccupation, which can be translated to various sexual activities. They also have lower sexual anxiety and fear of sex than less assertive ones (Heaven et al., 2003). Extraversion, a correlate of assertiveness, predicted higher interest in sex (Nettle, 2005). Moreover, the level of assertiveness fluctuates with hormonal changes in highly assertive women during their menstrual cycles, and it tends to be increased at times when women's conception is most likely (Hromatko et al., 2008). This finding implicates that a rise in assertiveness around ovulation might function as an enhancer of proactivity, which promotes an active pursuit for an available mate. Indeed, fertile women exhibited more interest in attending social gathering where they might meet men (Haselton \& Gangestad, 2006).

In line with these findings, several studies have shown the relationship between personality traits related to approach behavior in social interactions and sexual behavior. 
For example, high self-monitors, those who exhibit an active, initiatory, and directive approach to social interaction, had many sexual partners (Sakaguchi et al., 2007). More masculine men and women have been shown to seek short-term mating strategies (i.e., preference for casual sex and one-night stands) and have more number of sexual partners than less masculine and more feminine men and women (Mikach \& Bailey, 1999; Reise \& Wright, 1996). These findings suggest that the characteristics of assertiveness may reflect the degree of masculinization versus feminization of the brain. It is probably because testosterone $(\mathrm{T})$ exposure in utero has organizational effects on fetal brain development, which is long lasting effects on adult behaviors that show sex differences, including sexual behavior, gender role identity, and personality traits (Hines, 2011). It would seem probable that high prenatal $\mathrm{T}$ increases sexual motivation, lower sexual anxiety and fear of sex, or increases interest in short-term relationships, and these effects may be common to both sexes. That is, the characteristics of assertiveness and sexual behavior are affected by a common underlying physiological mechanism, prenatal $\mathrm{T}$. In a sense, more assertive men and women may be more likely to engage in casual sex and multiple partner relationships than less assertive men and women.

Furthermore, few studies have reported direct association between the characteristics of assertiveness and fertility. For example, leadership personality during adolescence and sociality in both sexes predicted adulthood fertility (e.g., the number of children and probability of having the first and second child; Jokela \& Keltikangas-Järvinen, 2009; Jokela, Kivimaki, Elovainio, \& Keltikangas-Jarvinen, 2009). It has also been shown that highly extroverted individuals (i.e., those with high sociality) have a greater number of sex partners, are more likely to engage in extra-pair copulation, terminate a relationship for new ones, and have more offspring (Alvergne et al., 2010; Nettle, 2005). All these findings indicate that assertiveness may have mating advantages to both men and women. Thus, we expect that highly assertive men and women will have a large number of sexual partners. An early onset of sexual activity, which is associated with first birth (Ellis, Figueredo, Brumbach, \& Schlomer, 2009), can also increase the lifetime mating success of both sexes (Belsky, Steinberg, Houts, \& Halpern-Felsher, 2010; Rhodes, Simmons, \& Peters, 2005). Thus, we also expect that more assertive individuals will have earlier first sexual experience than less assertive ones.

On the other hand, responsiveness is characterized as helpful, understanding, sincere, friendly, and sympathetic and compassionate to others (Richmond \& McCroskey, 1990). It is considered to be a key part of the feminine gender role and overlapped with characteristics of agreeableness. Highly responsive individuals exhibit excessive sensitivity to other's feeling or needs and willing to be sensitive to the talk of others by suspending their own concerns (Richmond \& McCroskey, 1992; Thompson et al., 1990). Hence, responsiveness tends to promote cooperation with unrelated same sex partners and be much valued as friends and coalitional partners (Hay, 1994; Michalski \& Shackelford, 2010; Nettle, 2006). It has also been shown that responsiveness associates with relationship satisfaction and the maintenance of relationship longer in committed couples (Bemis, 2008) because of their prosociality (e.g., altruism and generosity; Jensen-Campbell, Graziano, \& West, 1995).

However, excessive sensitivity to others' needs and unconditional trust of others are 
almost never an adaptive strategy because mating success varies depending on where and how individuals invest their limited time and resources (Andersson, 1994; Nettle, 2006; Trivers, 1972).

Therefore, from an evolutionary standpoint, highly responsive individuals may have costs in mating competition because they spend their time and energy more on others than their own mating effort, resulting in reduced personal fitness gains. Consistent with this idea, Bogaert and Fisher (1995) reported a non-significant negative association between social intimacy/closeness and lifetime sexual partner numbers in men. Gurven, von Rueden, Stieglitz, Kaplan, and Rodriguez (2014) also found that prosociality and agreeableness (i.e., empathy, sincere, sympathetic) were not associated with fertility (as measured by lifetime number of sex partners and number of surviving children) for both men and women. Based on theoretical considerations and previous findings, we expect that responsiveness will have null or negative effects on sexual behaviors in both sexes.

However, high responsiveness (e.g., understanding, sympathetic, generosity, etc.) may promote net mating benefits when accompanied by high assertiveness. Evolutionary theory and genetic evidence have implicated the inter-linkage of distinct personality traits to mating success; that is, those personality traits work well together in competition for mates, but not well alone (Lukaszewski, 2013). Thus, it is possible that high responsiveness may have mating advantages when accompanied by high assertiveness, but not work well alone. This is probably because the high assertiveness is the characteristics necessary to defend one's reproductive interests in the face of potential exploitation by many cooperative partners. Moreover, individuals with high in both characteristics may be competent communicators who behave flexibly across situations (McCroskey, 1994). Consistent with this idea, several studies have shown that individuals high in both characteristics were rated as being more attractive, had the highest self-rated mate value, and were preferred for short- and long-term partners as mates (Cramer, Cupp, \& Kuhn, 1993; Green \& Kenrick, 1994; Hromatko et al., 2008). In another study (Jensen-Campbell et al., 1995), women rated men who are dominant and agreeable as the most attractive mates. These findings suggest that high levels of both assertiveness and responsiveness, which allow individuals to display a context-dependent behavior, may provide mating advantages. Theoretically, if highly assertive individuals also possess high responsiveness, these individuals may be able to simultaneously invest their time and resources to both fitness gain and cooperation with unrelated partners. Accordingly, these individuals would have selective advantage in a mate competition. Thus, we tested the possible interaction effects of assertiveness and responsiveness on sexual behaviors.

However, high assertiveness and/or possibly behavioral flexibility may not be an optimal factor for mating success without considering body attractiveness. This is because body attractiveness is an important fitness-enhancing features, which signal health (e.g., lower rates of mortality and heart disease), social status, genetic quality (e.g., high physical symmetry), and fertility and are preferred as mates (Puts, Welling, Burriss, \& Dawood, 2012; Singh \& Singh, 2011; Welborn, Dhaliwal, \& Bennett, 2003; Zaadstra et al., 1993). Thus, we examined the possible interaction effects of assertiveness and responsiveness on body attractiveness, as measured by waist-to-hip ratio (WHR) for women and shoulder-to- 
hip ratio (SHR) for men. We also expect that physically attractive individuals with high assertiveness may not be able to optimize mating advantages if they are low in responsiveness, but if they are very assertive and responsive; the effects of body attractiveness would be increased beyond that predicted by either assertiveness or responsiveness alone.

Although there are a large number of independent studies related to the roles of personality and physical traits on sexual behavior, no studies have investigated the relative contributions of these traits to sexual behavior. Thus, we tested the relative importance of personalities compared to physical traits in predicting sexual behavior. Three physical traits were contemplated in this study: body shapes (WHR for women and SHR for men), fluctuating asymmetry (FA), digit ratios (2D:4D), which are affected by prenatal and adult sex hormones and play important role in fitness gains. 2D:4D is a sexually dimorphic trait that is influenced by the level of $\mathrm{T}$ relative to estrogen (E) in utero, as males tend to have lower 2D:4D, indicating higher $\mathrm{T}$ relative to $\mathrm{E}$, than females (Lutchmaya, Baron-Cohen, Raggatt, Knickmeyer, \& Manning, 2004; Manning, 2002). The surge of gonadal steroids at puberty affects the body shapes, with higher T/E ratios in men and women with higher WHR and SHR (Carranza-Lira, Velasco Diaz, Olivares, Chan Verdugo, \& Herrera, 2006; Kasperk, Wakley, Hierl, \& Ziegler, 1997; Singh \& Singh, 2011). FA, an indicator of the developmental imprecision, also partially show the influence of sex hormones, with higher E levels in women with low finger FA than those with high finger FA (Jasienska, Lipson, Ellison, Thune, \& Ziomkiewicz, 2006).

With regard to sexual behavior, attractive body shapes (high SHR in men and low WHR in women) and low FA, a marker of better genetic and phenotypic quality, predicted mate preferences and sexual behavior including earlier first sexual experiences, more lifetime sex partners, and higher sexual infidelity than their counterparts (Dijkstra \& Buunk, 2001; Gangestad \& Thornhill, 1997; Hughes \& Gallup, 2003; Møller \& Swaddle, 1997; Singh \& Singh, 2011; Thornhill \& Gangestad, 1994). Right 2D:4D (not left) was negatively associated with number of sex partners in college men (Honekopp, Manning, \& Muller, 2006) and higher sociosexuality scores, indicating higher interested in casual sex and short-term relationships, in college women (Clark, 2004) although other studies did not find significant associations (Putz, Gaulin, Sporter, \& McBurney, 2004; Rahman, Korhonen, \& Aslam, 2005). Based on these empirical findings, we tested the relative contributions of assertiveness, responsiveness, and fitness indicators (body shape, FA, and 2D:4D) to the prediction of sexual behavior.

\section{Methods}

\section{Participants}

Ninety men $($ mean age $=18.60$, range $18-24, \mathrm{SD}=1.08)$ and 138 women $($ mean $=18.59$, range $18-24$, $\mathrm{SD}=1.03$ ) college undergraduates were recruited from the research pool at the University at Albany. Sixtysix men and seventy-nine women were identified as white. The remaining participants were African-American, Hispanic, and Asian. All participants were given informed consent, approved by the University Institutional Review Board. 
Measures and Procedures

This study used multiple measurements, including self-perception of assertiveness, responsiveness, objective measures of physical fitness indicators (e.g., body shapes, FA, and 2D:4D), self-rated body attractiveness, sexual approaching behavior, and sexual behaviors.

Richmond and McCroskey's (1990) Assertiveness-Responsiveness measure was used. It consists of 10 assertiveness and 10 responsiveness items, which are commonly used to assess communication style and other social behavioral patterns. Each item was rated on a 7-point scale $(1=$ very unlikely to $7=$ extremely likely $)$. To assess sexual behavior, participants were asked to complete two items: number of sex partners [i.e., How many different partners have you had sex (sexual intercourse) throughout your life?] and age at first sexual intercourse. To assess sexual approach behavior, the two sexual tactics, Attract Opposite Sex and Use Sex, that can be used to find or attract available mates were adopted from Hierarchical Negotiation Tactics (Lund, Tamnes, Moestue, Buss, \& Vollrath, 2007). Attract Opposite Sex is comprised of three questions (i.e., Try to be attractive to the opposite sex, be seen with members of the opposite sex, and try to be more attractive to the opposite sex) and Use Sex includes three questions (i.e., have sex to get ahead, sleep with boss or co-worker, and flirt with someone to get something). Each question is rated on a 7-point scale (ranging from $1=$ very unlikely to $7=$ very likely). Questions about personal information included age, ethnicity, and annual family income for both sexes and oral contraceptive use (yes/no) for women. Each participant was also asked to rate his or her body attractiveness $(1=$ very unattractive to $5=$ very attractive $)$ and sexual orientation $(1=$ exclusively heterosexual to $7=$ exclusively homosexual $)$.

The circumference of the shoulder, waist, and hips were measured twice with a body measuring tape accurate to the $0.1 \mathrm{~cm}$. Absolute agreement intra-class correlation coefficients (ICCs) were used to assess remeasurement reliability (all $r_{1}=.99$ ). Then, each score obtained from body measurements was transferred into WHR and SHR. Body mass index (BMI) was calculated as (body mass in $\mathrm{kg}) /(\text { height in } \mathrm{m})^{2}$. For FA, a single score of composite fluctuating asymmetry $(\mathrm{CFA}), \mathrm{CFA}=\left[\sum|(\mathrm{R}-\mathrm{L}) /(\mathrm{R}+\mathrm{L}) / 2|\right]$, for each subject was calculated using the six bilateral body traits (ear width and length, wrist width, elbow width, ankle width, and hand width). Each trait was measured twice using a digital caliper accurate to $0.01 \mathrm{~mm}$, ICCs for singed FAs $(\mathrm{R}-\mathrm{L})=0.761-0.960$. A two-way, mixed model analysis of variance (ANOVA) revealed that interindividual variability in FAs were significantly higher than measurement error for the six bilateral morphological traits, ranged from 7.352 to 49.460 , all $p<.001$. Using hand scans, the $2^{\text {nd }}$ and $4^{\text {th }}$ finger digit lengths were measured by the measurement tool ( $0.01 \mathrm{~mm}$ accuracy) in Adobe Acrobat 7.0 Professional. Each finger was measured twice on the palmar surface from tip to basal crease and these measurements were averaged to obtain a final length measurement (ICC $=r_{l}=.997-r_{l}=.999$ ). The $2 \mathrm{D}: 4 \mathrm{D}$ ratios were calculated by dividing the secondfinger length by the fourth-finger length.

\section{RESUlts}

Prior to analysis, two univariate outliers (3 SD above and below the mean of the variables, two females) were deleted, and remaining 90 males and 136 females were used for analyses. After deleting outliers the range of WHR and SHR were $0.65-0.88$ and 0.89-1.17 for women and $0.73-0.92$ and 1.00-1.26 for men, respectively. To reduce extreme skewness and kurtosis, number of sex partners was logarithmically transformed $[\ln ($ number of sex partners +1$)]$. In consideration of the possible nonlinear relationship between body shapes and number of sex partners (Frederick \& Haselton, 2007), the curvilinear relationships between these variables were assessed using regression curve estimation. No significant curvilinear relationships were found in both men [quadratic term: WHR, $\mathrm{F}(2,87)=.924 ; \operatorname{SHR}, \mathrm{F}(2,87)=.965$, all n.s.] and women [quadratic term: WHR, $\mathrm{F}(2,133)=.355$; SHR, $\mathrm{F}(2,105)=.137$, all n.s.]. Previous studies have reported that women's contraceptive use, with higher sociosexuality scores in contraceptive users than in non-users (Clark, 2004), and BMI (Swami \& Tovee, 2005) affect their sexual 
Table 1. Descriptive statistics.

\begin{tabular}{|c|c|c|c|c|}
\hline & Males & Females & \multirow{2}{*}{$\mathrm{t}(\mathrm{p})$} & \multirow{2}{*}{ Cohen'd } \\
\hline & Mean (SD) & Mean (SD) & & \\
\hline WHR & $.80(.04)$ & $.74(.04)$ & $10.661(<.001)$ & -1.50 \\
\hline SHR & $1.14(.05)$ & $1.04(.05)$ & $15.338(<.001)$ & -2.00 \\
\hline Right 2D:4D & $.95(.03)$ & $.96(.03)$ & $-2.640(.009)$ & .33 \\
\hline Left 2D:4D & $.95(.03)$ & $.96(.03)$ & $-2.976(.003)$ & .33 \\
\hline FA & $.09(.04)$ & $.10(.05)$ & $-1.822(.070)$ & .23 \\
\hline Assertiveness & $5.07(.77)$ & $4.97(.88)$ & $.858(.392)$ & -.12 \\
\hline Responsiveness & $5.25(.77)$ & $5.46(.82)$ & $-1.934(.054)$ & .26 \\
\hline Self-assessed attractiveness & $3.48(.82)$ & $3.58(.81)$ & $-.929(.354)$ & .12 \\
\hline Attract opposite sex & $5.68(.89)$ & $5.36(1.35)$ & $1.955(.052)$ & .28 \\
\hline Use sex & $3.23(1.42)$ & $2.31(1.03)$ & $5.692(<.001)$ & -.77 \\
\hline Age at $1^{\text {st }}$ sex & $16.06(1.42)$ & $16.29(1.42)$ & $-1.066(.288)$ & .16 \\
\hline $\ln ($ No. of sex partners +1$)$ & $1.12(.80)$ & $1.04(.78)$ & $.742(.459)$ & -.10 \\
\hline
\end{tabular}

$\mathrm{WHR}=$ waist-to-hip ratio, $\mathrm{SHR}=$ shoulder-to-hip ratio, $2 \mathrm{D}: 4 \mathrm{D}=$ second-to-forth finger ratio, $\mathrm{FA}=$ fluctuating asymmetry.

behavior. Thus, the group differences of oral contraceptive use (users $=1$, non-users $=0$ ) in sexual behaviors and other variables were tested with an independent-samples t-test, and the correlation between BMI and number of sex partners were assessed. The result showed that the only group difference was found in number of sex partners, but not for other variables. Women using oral contraceptive $(20.8 \%$ of women, $\mathrm{N}=47)$ had more number of sex partners than those not using oral contraceptive $(\mathrm{t}=-2.839, \mathrm{p}=.005)$. No significant relationship was found between BMI and women's partner numbers in the current sample $(\mathrm{r}=-.03$, n.s.).

\section{Descriptive Statistics \& Correlations}

As shown in Table 1, assertiveness was not significantly different between sexes, while responsiveness scores tend to be higher for women than men. Significant sex differences were found in physical fitness indicators, except for CFA. With regard to the use of tactics, men used sexual tactics more often than women, particularly use sex tactic $(t=5.692, p<.001)$. However, age of first sexual intercourse and number of sexual partners were not significantly different between sexes.

Assertiveness was significantly correlated with sexual behavior in both sexes, but not responsiveness (see Table 2). Highly assertive men and women had more number of sex partners (males, $\mathrm{r}=.44, \mathrm{p}<.001$, Cohen's $\mathrm{d}=.98$; females, $\mathrm{r}=.28, \mathrm{p}=.001, \mathrm{~d}=.58$ ) and earlier onset of first sexual experience (males, $\mathrm{r}=-.33, \mathrm{p}=.004, \mathrm{~d}=-.70$; females, 
PERSONALITY \& SEXUAL BEHAVIOR

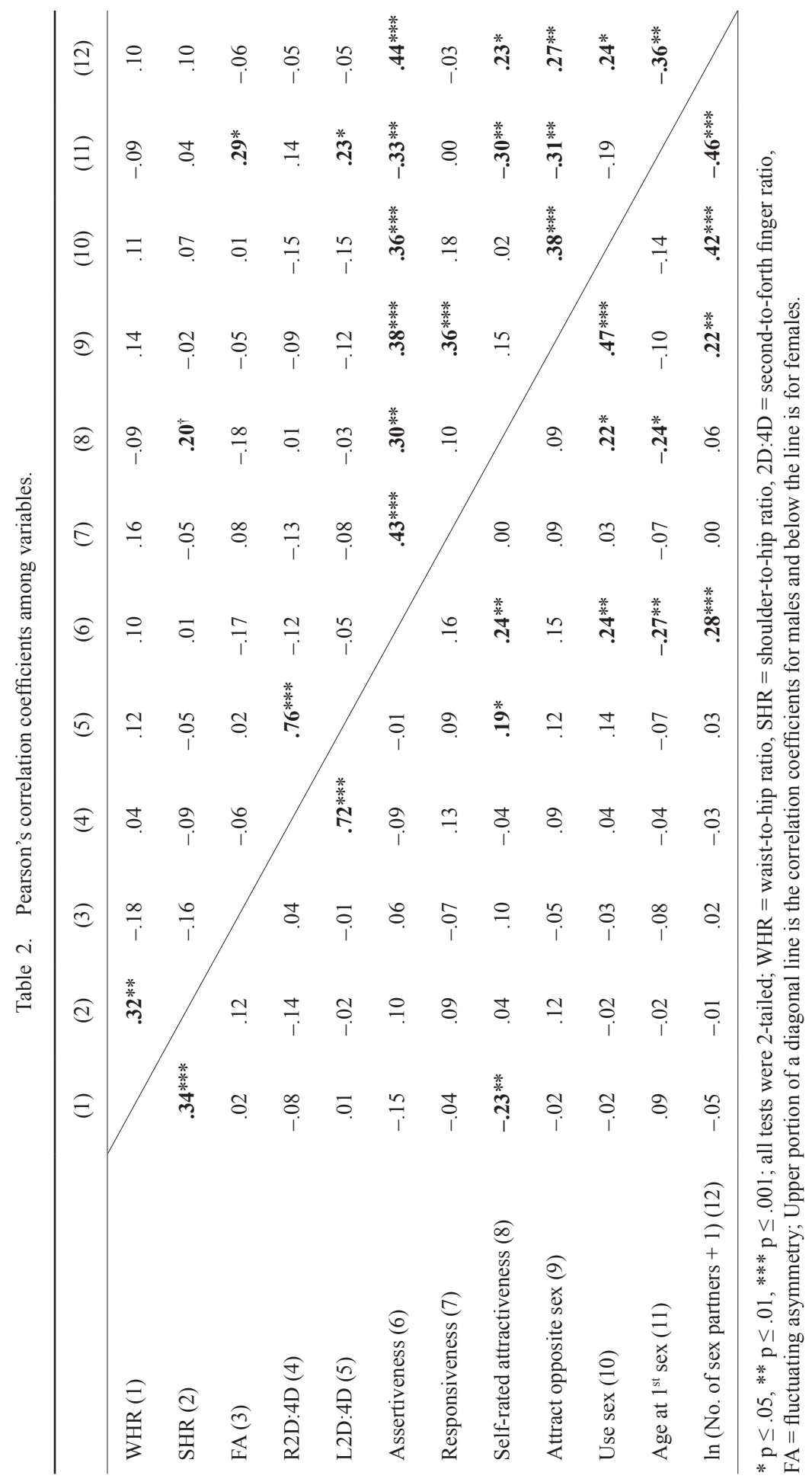


$\mathrm{r}=-.27, \mathrm{p}=.006, \mathrm{~d}=-.56)$ than less assertive ones. They also perceived themselves as more physically attractive (males, $r=.30, p=.005, d=.63$; females, $r=.24, p=.006$, $\mathrm{d}=.50)$ and used sexual tactics more often, compared to less assertive ones. Women with lower WHR $(\mathrm{r}=-.23, \mathrm{p}=.007, \mathrm{~d}=-.47)$ and higher left 2D:4D $(\mathrm{r}=.19, \mathrm{p}=.028, \mathrm{~d}=.39)$ rated themselves as being more physically attractive. For men, SHR was not significantly associated with self-rated attractiveness $(\mathrm{r}=.20, \mathrm{p}=.064, \mathrm{~d}=.41)$. However, after controlling for age and ethnicity, a significant association was observed $(\mathrm{r}=.23, \mathrm{p}=.037$, $\mathrm{d}=.47$ ). Earlier first sexual experience was associated with a greater number of sexual partners for both sexes.

\section{The interaction effects of personalities and body attractiveness}

Hierarchical multiple regression analyses were performed to test the interaction effects of assertiveness, responsiveness, and body attractiveness on predicting sexual behaviors. We included only WHR for women and SHR for men as measures of body attractiveness in these analyses because WHR and SHR accounted for more variance in women and men's sexual behavior than SHR and WHR, respectively (Dijkstra \& Buunk, 2001; Hughes \& Gallup, 2003). Age, ethnicity, and sexual orientation were controlled for predicting number of sex partners and ethnicity for age of first sexual intercourse. Oral contraceptive use was also controlled for predicting women's partner numbers because it was significantly correlated with number of sex partners. Control variables were first entered, followed by assertiveness, responsiveness, body shape in the second step, twoway interactions in the third step, and then a three-way interaction in the fourth step. All independent variables were standardized to reduce possible multicollinearity problems by adding interactions between variables. The two separated hierarchical multiple regression analyses for each sex were conducted.

Men. Three-way interactions were not significant, and thus, they were removed from the model. Overall model was significant for number of sex partners, $F(11,78)=5.561$, $\mathrm{p}<.001, \mathrm{R}^{2}=.44$, and age of first sex, $\mathrm{F}(9,63)=5.242, \mathrm{p}<.001, \mathrm{R}^{2}=.43$. As shown in Figure 1, the relationship between SHR and sexual behavior was moderated by either assertiveness (number of sexual partners, $\beta=.20, \mathrm{p}=.047, \mathrm{sr}^{2}=.03$ ) or responsiveness (number of sexual partners, $\beta=.21, \mathrm{p}=.028, \mathrm{sr}^{2}=.04$; age of first sexual intercourse, $\beta=-.28, \mathrm{p}=.011, \mathrm{sr}^{2}=.06$ ). To probe the interaction between SHR and personality traits, post hoc test was conducted using the simple slopes analysis (Aiken \& West, 1991). At high level of assertiveness men's sexual partner numbers significantly increased with SHR $(t=2.08, p=.041)$, whereas at low level of assertiveness non-significant negative effect was observed $(t=-.790, n$.s. $)$. With regard to responsiveness, at high level of responsiveness men with low SHR had the lowest number of sexual partners, but men's number of sexual partners significantly increased with $\operatorname{SHR}(t=3.040, p=.003)$. However, at low level of responsiveness non-significant negative effect was observed $(t=-.775$, n.s. $)$. For age of $1^{\text {st }}$ sex, at high responsiveness there was a significant negative effect with SHR $(t=-2.027$, $p=.047)$, but positive effect at low responsiveness $(t=2.380, p=.020)$.

Women. A three-way interaction between assertiveness, responsiveness, and body attractiveness was significant for number of sex partners. However, no significant three- 

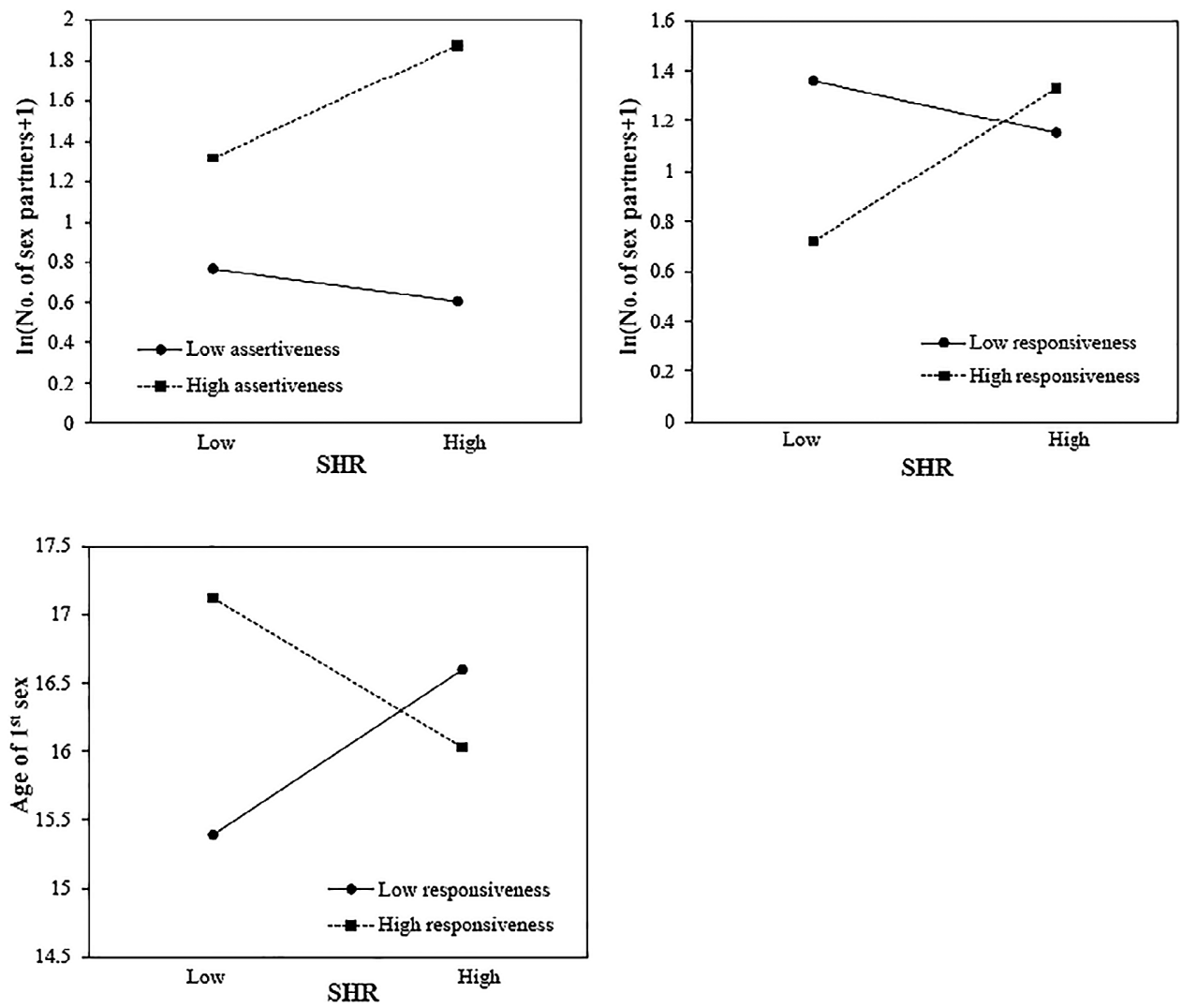

Fig. 1. The moderating effect of assertiveness and responsiveness on the relationship between SHR (shoulder-to-hip ratio) and sexual behaviors in men. Note. Low $=\mathrm{M}-1 \mathrm{SD}$; high $=\mathrm{M}+1 \mathrm{SD}$.

way interaction was found for age of first sexual intercourse, which was removed from the model. Overall model was significant for number of sex partners, $F(13,122)=4.108$, $\mathrm{p}<.001, \mathrm{R}^{2}=.30$, and age of first sex, $\mathrm{F}(9,91)=3.301, \mathrm{p}=.002, \mathrm{R}^{2}=.25$. As shown in figure 2 , the two-way interaction between assertiveness and responsiveness was statistically significant in predicting age of first sex (WHR, $\left.\beta=.33, \mathrm{p}=.002, \mathrm{sr}^{2}=.08\right)$. Post hoc test (Aiken \& West, 1991) revealed that at low level of responsiveness women's age of $1^{\text {st }}$ sexual experience decreased with assertiveness $(t=-4.490, p<.001)$, whereas at high level of responsiveness non-significant negative effect was observed $(t=-.642, n$.s. $)$. That is, women who are high in assertiveness and low in responsiveness had the earliest age of first sexual experience.

This combined effect of assertiveness and responsiveness interacts with body shape measure in predicting number of sexual partners (WHR, $\beta=.20, \mathrm{p}=.018, \mathrm{sr}^{2}=.03$ ) (see Fig. 3). At high assertiveness and low responsiveness, women with low WHR had a greater number of sex partners than other combinations of body shape and personality traits. However, this effect followed by a decline in partner numbers with increase in WHR. 


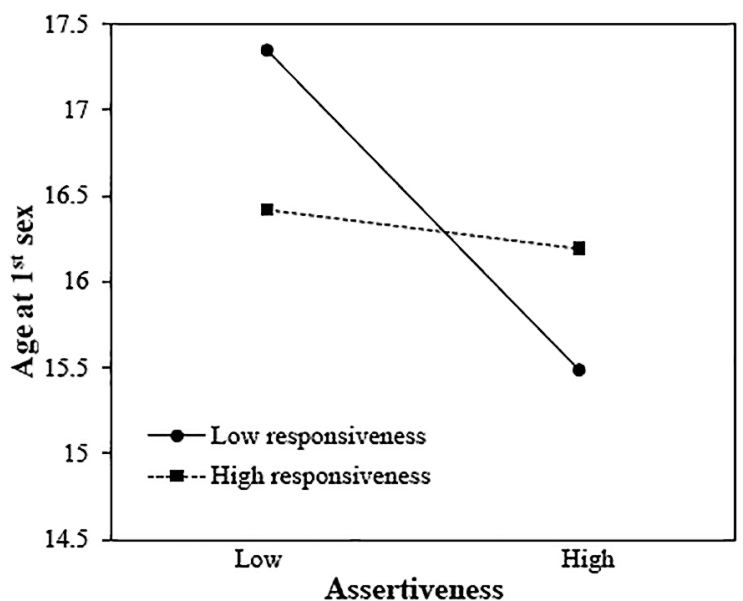

Fig. 2. The interaction effect of assertiveness and responsiveness in predicting age at $1^{\text {st }}$ sexual intercourse in women. Note. Low $=\mathrm{M}-1 \mathrm{SD}$; high $=\mathrm{M}+1 \mathrm{SD}$.

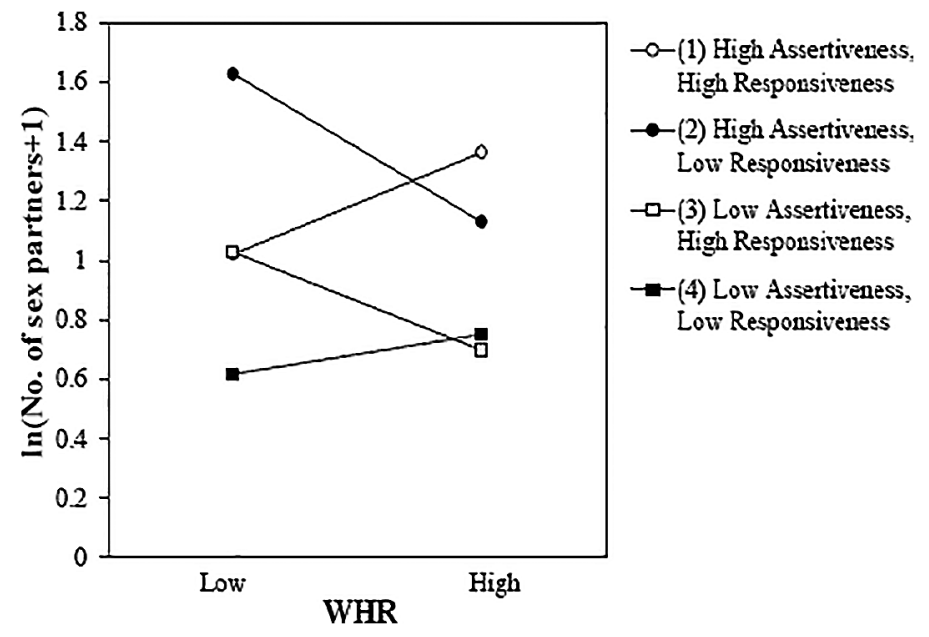

Fig. 3. The moderating effect of assertiveness and responsiveness on the relationship between WHR (waistto-hip ratio) and number of sex partners in females. Note. Low $=\mathrm{M}-1 \mathrm{SD}$; high $=\mathrm{M}+1 \mathrm{SD}$.

Moreover, women who are high in both assertiveness and responsiveness were likely to have a larger number of sex partners when they have high WHR, rather than low WHR. At the low level of both assertiveness and responsiveness, WHR had no predictive effect on women's partner numbers.

To test whether the level of responsiveness makes a difference to the relation between body shape and number of sex partners for highly assertive women, the slope difference test (Dawson \& Richter, 2006) for number of sex partners was estimated, a test for the slope of (1) and (2) (see Fig. 3). In the prediction of the effects of WHR on number of sex 
Table 3. Hierarchical multiple regression analyses.

\begin{tabular}{|c|c|c|c|c|c|}
\hline & \multirow{3}{*}{ Predictor } & \multicolumn{2}{|c|}{$\ln ($ No. of sex partners +1$)$} & \multicolumn{2}{|c|}{ Age of $1^{\text {st }}$ sex } \\
\hline & & Men & Women & Men & Women \\
\hline & & $\beta\left(\mathrm{sr}^{2}\right)$ & $\beta\left(\mathrm{sr}^{2}\right)$ & $\beta\left(\mathrm{sr}^{2}\right)$ & $\beta\left(\mathrm{sr}^{2}\right)$ \\
\hline \multirow[t]{6}{*}{ Step 1} & Age & $.27(.07)^{* *}$ & $.08(.01)$ & - & - \\
\hline & White & $.49(.11)^{* * *}$ & $.34(.05)^{* *}$ & $-.52(.08)^{* *}$ & $-.24(.02)$ \\
\hline & Black & $.50(.14)^{* * *}$ & $.13(.01)$ & $-.85(.26)^{* * * *}$ & $-.02(.00)$ \\
\hline & Hispanic & $.12(.01)$ & $.12(.01)$ & $-.33(.06)^{*}$ & $-.12(.01)$ \\
\hline & Sexual orientation & $.10(.01)$ & $.21(.04)^{*}$ & - & - \\
\hline & Contraceptive use & - & $.15(.02)$ & - & - \\
\hline \multirow[t]{8}{*}{ Step 2} & WHR & - & $-.07(.00)$ & - & $.09(.01)$ \\
\hline & SHR & $.13(.02)$ & - & $.04(.00)$ & - \\
\hline & Right 2D:4D & $-.01(.00)$ & $-.03(.00)$ & $.04(.00)$ & $-.00(.00)$ \\
\hline & FA & $.05(.00)$ & $-.02(.00)$ & $.12(.01)$ & $-.08(.01)$ \\
\hline & Assertiveness & $.46(.14)^{* * *}$ & $.30(.08)^{* * *}$ & $-.23(.04)^{\dagger}$ & $-.32(.09)^{* *}$ \\
\hline & Responsiveness & $-.22(.04)^{*}$ & $-.06(.00)$ & $.14(.02)$ & $-.04(.00)$ \\
\hline & $\mathrm{F}$ & $4.592 * * *$ & $3.904^{* * *}$ & $4.689 * * *$ & $2.100^{*}$ \\
\hline & $\mathrm{R}^{2}$ & .368 & .257 & .370 & .154 \\
\hline
\end{tabular}

${ }^{\dagger} \mathrm{p} \leq .10, * \mathrm{p} \leq .05, * * \mathrm{p} \leq .01, * * * \mathrm{p} \leq .001 ; \mathrm{sr}^{2}=$ squared semi-partial correlation coefficient (incremental); $\mathrm{WHR}=$ waist-to-hip ratio, $\mathrm{SHR}=$ shoulder-to-hip ratio, $2 \mathrm{D}: 4 \mathrm{D}=$ second-to-forth finger ratio, $\mathrm{FA}=$ fluctuating asymmetry; SHR for men and WHR for women.

partners, the difference between the slope of (1) and (2) was statistically significant $(\mathrm{t}=2.100, \mathrm{p}=.038)$. Specifically, for highly assertive women who are also highly responsive, there was a positive relationship between WHR and sex partner numbers. This was significantly different from a negative relation for those women scored low in responsiveness.

The relative contributions of personality and physical traits to the prediction of sexual behavior

Hierarchical multiple regression analyses were performed to test which variables are better at predicting sexual behavior. Control variables, same as above regression analyses, were first entered, followed by assertiveness, responsiveness, body shape (WHR for women and SHR for men), FA, and right 2D:4D in the second step. The two separated hierarchical multiple regression analyses for each sex were conducted.

Men. Personality traits and physical fitness indicators together were accounted for $20 \%$ of variance in number of sex partners after controlling for confounding variables, 
$\mathrm{F}(10,79)=4.592, \mathrm{p}<.001$. Among those, most of the variance was explained by assertiveness (13.8\%) and responsiveness (3.5\%), with only $1.7 \%$ remaining for the three physical fitness indicators together (SHR, CFA, and right 2D:4D; see Table 3). Assertiveness positively predicted partner numbers $(\beta=.46, \mathrm{p}<.001)$, whereas responsiveness had a negative relationship with number of sex partners $(\beta=-.22, p=.039)$. Men's age of first sexual experience tended to decrease with assertiveness $(\beta=-.23, p=.058)$, whereas nonsignificant positive relationship was found between responsiveness and age of first sexual intercourse $(\beta=.138$, n.s. $)$.

Women. Most of the variance in number of sex partners was explained by assertiveness, $7.6 \%$ of $8.4 \%$ of variance in all predictors together (WHR, 2D:4D, FA, assertiveness, and responsiveness) after controlling for confounding variables, $F(11,124)=3.904, p<.001$. More assertive women had higher numbers of sex partners than less assertive women $(\beta=.30, \mathrm{p}=.001)$, whereas responsiveness had no predictive effect $(\beta=-.06$, n.s.; see Table 3). Women's assertiveness was also a strong predictor of age of first sexual intercourse $(\beta=-.32, p=.002)$, accounting $9.1 \%$ of $10.6 \%$ of variance in all predictors together after controlling for confounding variables, WHR, $F(8,92)=2.100, p=.044$.

\section{DISCUSSION}

Assertiveness had substantial effects on sexual behaviors (i.e., a larger number of sex partners and earlier onset of first sexual experience) in both sexes, whereas responsiveness had negative effects in men and null effects in women. Highly assertive men and women also perceived themselves as more physically attractive and showed more active sexual access (i.e., use of try to attract opposite sex and use sex tactics more often) than less assertive ones. Among personality traits and physical fitness indicators, assertiveness was a primary predictor of number of sex partners in both sexes, accounting for $14 \%$ of variance in men and $7.6 \%$ in women after controlling for confounding variables. Thus, it is concluded that personality traits, particularly assertiveness, are a better predictor of sexual behavior, compared to physical traits. Moreover, interaction effects indicate that mating success is also an outcome of the concerted interplay of personalities and body attractiveness. Findings support the evolutionary hypotheses that personality traits are alternative adaptive strategies evolved as a means of ensuring fitness (Alvergne et al., 2010; Buss, 1991; Nettle, 2005).

The relationships of assertiveness and responsiveness to approach and sexual behavior indicate that interindividual differences in personality traits linked to communication and social interaction patterns influence differential mating outcomes. These results are parallel to the previous studies of the positive relations of self-monitoring, extraversion and low agreeableness to unrestricted sociosexuality, a tendency to engage in casual sex and multipartner relationships (Sakaguchi et al., 2007; Wright \& Reise, 1997). Findings also provide some support for the notion that sexually active approach behavior has mating benefits: securing mate numbers and quality (Nettle, 2006). However, it should be considered that the findings of responsiveness on sexual behavior, negative effects in men and null in 
women, are not to mean that responsiveness has lifetime fitness costs. Possibly, assertive and responsive individuals may achieve their lifetime reproductive success through different means. For example, assertive women could have reproductive advantages through mating with men of high genetic fitness passed on their children, and it can be achieved by gaining first access to high quality men (see Gangestad \& Simpson, 1990 for detail about the association between women's partner numbers and chance of gaining men with good genes). For men, those who are assertive could benefit from many female sexual partners. On the other hand, responsive men and women, those who put more time and efforts to commitment, may have reproductive benefits through parental investment in their children.

It is worth noting that women's active sexual access and many sexual partners could have fitness costs, with potential exploitation by men who engage in casual sex and seek multiple sexual partners and also possibly with the rape and sexual assault victimization. Testa, VanZile-Tamsen, and Livingston (2007) confirmed this possibility showing that number of sexual partners was a risk factor for sexual victimization, with high rates of sexual victimization among women with many sexual partners. However, the studies of the relationship between personality and sexual victimization suggested that high assertiveness may depend herself from unwanted sexual advances. It is probably because the characteristics of high assertiveness are a set of refusal behaviors (e.g., knowing how and when to say no) occurring the context of partner insistence and pressure (Richmond \& McCroskey, 1992; Walker \& Messman-Moore, 2011). Consistent with this notion, several studies found a negative association between assertiveness and sexual victimization (MacGreene \& Navarro, 1998) and a lower sexual assertiveness in revictimized women than nonvictims (Kearns \& Calhoun, 2010). Finally, Walker and Messman-Moore (2011) recently reported that the relationship between sexual partner numbers and sexual victimization was moderated by the levels of assertiveness. Specifically, among women who had a larger number of sexual partners, highly assertive women had fewer experience of sexual coercion than less assertive ones. Thus, highly assertive women who have many sexual partners would be less likely to be exploited by men who seek multiple partners, rape, or coercion.

Personality traits accounted for much more variance in number of sex partners (approximately 10.2 times higher in men and 15.8 in women) and age of first sex (about 3.7 times higher in men and 7.2 in women), compared with physical fitness indicators together. Moreover, interaction effect revealed that women who were low in both assertiveness and responsiveness, noncompentent communicators (Anderson \& Martin, 1995), had the least number of sexual partners regardless of their body attractiveness. These findings indicate that variation in sexual behavior is much bigger for personality traits than physical traits, probably gaining insight into the magnitude of variation in traits under frequency-dependent selection and those under positive selection. Physical traits associated with fitness have been the substrate of varying levels of positive selection (Vallender \& Lahn, 2004). Positive selection that favors these beneficial traits eventually will drive variation to fixation through a runaway, implicating small variation in physical traits. On the other hand, diversity in expressive patterns of personality traits may be maintained through frequency-dependent 
selection, which is an evolutionary process where the optimal levels of reproductive fitness for a particular personality trait, depends on its frequency relative to other personality traits within the population in response to a socioecological context (Buss, 1991; Gangestad \& Simpson, 1990). Thus, it is possible that boundless genetic variance in personality traits could be maintained through selection for rare personality trait (Penke, Denissen, \& Miller, 2007), implicating large variation in those traits. It is the first finding that shows the relative contributions of personality traits and physical fitness indicators to sexual behavior. Thus, further research should be required to verify our findings.

Contrary to our expectations, physically attractive (low WHR) women who are high in assertiveness and low in responsiveness had the greatest number of sex partners, rather than those who are high in both characteristics. Although not as much of these women, women with high WHR (less attractive figure) also had more sexual partners when they display high in both characteristics, enabling them to be competent communicator who behavior flexibly across situations (e.g., being flexible and versatile). If so, why low WHR women who are high in both characteristics do not have maximal mating success? Why do low WHR women who are high in assertiveness and low in responsiveness have the greatest partner numbers? Why do a combination of high assertiveness and responsiveness offer high WHR women a greater mating success, rather than low WHR women?

A plausible explanation of this finding comes from a recent theoretical framework on evolutionary equilibrium where socially responsive and unresponsive individuals coexist (Johnstone \& Manica 2011; Wolf \& McNamara, 2012; Wolf, Van Doorn, \& Weissing, 2011). Here, socially responsive individuals are those who take into account the behavioral history of their social partners and thus can change the selective pressures for the traits they respond to. On the other hand, unresponsive individuals are those who show high levels of adaptive behavioral consistency by positive feedback mechanisms between fitness expectations and their behaviors. Based on these theoretical considerations, low WHR women may experience a positive feedback between body attractiveness, a fitnessenhancing trait, and high assertiveness and low responsiveness. As a consequence, they may display high levels of adaptive consistency in their behaviors, which always have maximal fitness (Wolf \& McNamara, 2012; Wolf et al., 2011). Thus, these women may not have to be as flexible and versatile as less attractive women because of their superior ability to gain many sexual partners. On the other hand, high WHR women (e.g., those who are less attractive) observe the behaviors of their social partners and adjust their behaviors accordingly, possibly adopting behavioral flexibility. Specifically, less attractive women may observe others' behaviors and think that exhibiting socially aversive personality characteristics (e.g., low empathy, altruism, and generosity) would have costs in their pursuit of friends and romantic partners as mentioned by Holtzman, Augustine, and Senne's (2011) study in the relationships between low FA and high socially aversive behaviors. Thus, these women may utilize context-dependent flexibility of behaviors, simultaneously exhibiting agency (e.g., being dominant, assertive, and exhibitionistic) and prosocial behavior (e.g., willingness to cooperate, empathy, and trust), to offset the mating costs they have experienced due to being less attractive across development. Probably, these women's behavioral adaptability would increase their attractiveness to men, resulting in more sexual 
partners. These findings may support for the notion that although behavioral flexibility has a selective advantage, it can be limited by behavioral consistency that can be advantageous because it makes individuals predictable (Wolf et al., 2011).

If so, why women who have both physical attractiveness and behavioral flexibility do not have the greatest mating opportunity? One of the possible explanations is conditiondependent behavior. According to this hypothesis, women raise or lower their standards in male mates on the bases of their own mate value (Buss \& Shackelford, 2008). Thus, attractive women who exhibit behavioral flexibility, indicators of high mate values, would be likely to be choosier than less attractive women, preferring high quality men in various ways (e.g., men who have good genes and superior economic resources and are willing to invest in partners and children). Accordingly, women's high standards in male mates would narrow the potential mating pool. Specifically, a small number of men will meet the demands of these women, resulting in reduced available men. The other explanation is male mate guarding, which is a mating strategy that secure their sexual partners from copulating with other men (Buss \& Shackelford, 2008; Haselton \& Gangestad, 2006). That is, women with high mate value may be hard to escape male mate guarding, resulting in lower mating opportunity with another men. Possibly it might be also true that men think that these women already have romantic partners, hence, limit access to these women.

Men's 2-way interactions suggests that maximizing men's mating success vary depending on body condition and the levels of either assertiveness or responsiveness. Assertiveness and responsiveness alone had positive and negative relationship, respectively, with sexual behavior. However, these personality traits yielded different outcomes according to men's body attractiveness. Specifically, highly assertive men who are physically more attractive had additional sexual opportunities, compared to those who are physically less attractive. Likewise, high responsiveness offers physically attractive men more number of sexual partners, whereas it decreases mating opportunity in less attractive men. That is, high responsiveness has a negative effect on men's mating opportunities for less attractive men, but not for physically attractive men. These findings indicate that highly responsive men who are physically less attractive may have costs in mating competition, probably because of their large investment of their energy more on others than their own mating effort. On the other hand, those men with physically attractive bodies may have remaining energy able to deal with mating costs after large investment on others due to their superior ability linked to body masculinity.

There are several limitations in the current study. The use of a college sample is a major limitation, the problem of generalizing findings from college sample to the general population. It is because college students are a very specific part of the population, and the consequence of personality traits on sexual behavior varies depending on socio-ecological context, such as culture and occupation (Buss, 1991). However, the pattern of assertivenesssexual behavior relation might be applicable to the general population. Thus, findings are needed for replication and confirmation in the general populations. Another possible methodological limitation is potential biases caused by reverse causality. Highly assertive men and women exhibited active approaching behavior, sexual experience at earlier age, and more sexual partners. Given these correlations, possibly assertiveness itself might 
prompt individuals to engage in active sexual behaviors. Alternatively, individuals who engage in more sexual activities might gain opportunity of being chosen as mates more often and this feeds into their psychological mechanisms, resulting in being assertive. Moreover, neither personality characteristics nor sexual behavior had a significant relationship with body attractiveness in both sexes, although many previous studies have shown the association between these variables. However, it is somewhat clear that body attractiveness exerts influence on sexual behavior in interaction with personality and that highly assertive men and women who are physically attractive enjoy exceptionally high mating success, compared to those who are less physically attractive. Future research is needed to explore this relationship. Possibly it might provide fruitful knowledge about the relationship between personality traits and sexual behavior.

\section{REFERENCES}

Aiken, L. S., \& West, S. G. 1991. Multiple regression: Testing and interpreting interactions. Newbury Park, CA: Sage.

Alberti, R. E., \& Emmons, M. L. 1995. Your perfect right: A guide to assertive living (25th anniversary 7 th ed.). San Luis Obispo, CA: Impact.

Alvergne, A., Jokela, M., \& Lummaa, V. 2010. Personality and reproductive success in a high-fertility human population. Proceedings of the National Academy of Sciences of United States of America, 107, 1174511750.

Anderson, C. M., \& Martin, M. M. 1995. Communication motives of assertive and responsive communicators. Communication Research Reports, 12, 186-191.

Andersson, M. 1994. Sexual selection. Princeton, NJ: Princeton University Press.

Barrett, H. C., \& Kurzban, R. 2006. Modularity in cognition: Framing the debate. Psychological Review, 113, 628-647.

Belsky, J., Steinberg, L., Houts, R. M., \& Halpern-Felsher, B. L. 2010. The development of reproductive strategy in females: Early maternal harshness $\rightarrow$ earlier menarche $\rightarrow$ increased sexual risk taking. Developmental Psychology, 46, 120-128.

Bemis, J. M. 2008. Emotional responsiveness, intimacy, and capitalization attempts in intimate relationships: A dyadic assessment (Doctoral dissertation). Retrieved from ProQuest. (UMI No. 3328290)

Bogaert, A. F., \& Fisher, W. A. 1995. Predictors of university men's number of sexual partners. The Journal of Sex Research, 32, 119-130.

Buss, D. M. 1991. Evolutionary personality psychology. Annual Review of Psychology, 42, 459-491.

Buss, D. M., \& Greiling, H. 1999. Adaptive individual differences. Journal of Personality, 67, 209-243.

Buss, D. M., \& Shackelford, T. K. 2008. Attractive women want it all: Good genes, economic investment, parenting proclivities, and emotional commitment. Evolutionary Psychology, 6, 134-146.

Carranza-Lira, S., Velasco Diaz, G., Olivares, A., Chan Verdugo, R., \& Herrera, J. 2006. Correlation of Kupperman's index with estrogen and androgen levels, according to weight and body fat distribution in postmenopausal women from Mexico City. International Journal of Fertility and Women's Medicine, 51, 83-88.

Clark, A. P. 2004. Self-perceived attractiveness and masculinization predict women's sociosexuality. Evolution and Human Behavior, 25, 113-124.

Cramer, R. E., Cupp, R. G., \& Kuhn, J. A. 1993. Male attractiveness: Masculinity with a feminine touch. Current Psychology, 12, 142-150.

Dawson, J. F., \& Richter, A. W. 2006. Probing three-way interactions in moderated multiple regression: Development and application of a slope difference test. Journal of Applied Psychology, 91, 917-926.

Dijkstra, P., \& Buunk, B. P. 2001. Sex differences in the jealousy-evoking nature of a rival's body build. Evolution and Human Behavior, 22, 335-341.

Ellis, B. J., Figueredo, A. J., Brumbach, B. H., \& Schlomer, G. L. 2009. Fundamental dimensions of 
environmental risk. Human Nature, 20, 204-268.

Frederick, D. A., \& Haselton, M. G. 2007. Why is muscularity sexy? Tests of the fitness indicator hypothesis. Personality and Social Psychology Bulletin, 33, 1167-1183.

Gangestad, S. W., \& Simpson, J. A. 1990. Toward an evolutionary history of female sociosexual variation. Journal of Personality, 58, 69-96.

Gangestad, S. W., \& Thornhill, R. 1997. Human sexual selection and developmental stability. In J. A. Simpson \& D. T. Kenrick (Eds.), Evolutionary social psychology (pp. 169-195). Mahwah, NJ: Erlbaum.

Green, B., \& Kenrick, D. 1994. The attractiveness of gender-typed traits at different relationship levels: Androgynous characteristics may be desirable after all. Personality and Social Psychology Bulletin, 20, 244-253.

Gurven, M., von Rueden, C., Stieglitz, J., Kaplan, H., \& Rodriguez, D. E. 2014. The evolutionary fitness of personality traits in a small-scale subsistence society. Evolution and Human Behavior, 35, 17-25.

Haselton, M. G., \& Gangestad, S. W. 2006. Conditional expression of women's desires and men's mate guarding across the ovulatory cycle. Hormones and Behavior, 49, 509-518.

Hay, D. F. 1994. Prosocial development. Journal of Child Psychology and Psychiatry, 35, $29-71$.

Heaven, P. C. L., Crocker, D., Edwards, B., Preston, N., Ward, R., \& Woodbridge, N. 2003. Personality and sex. Personality and Individual Differences, 35, 411-419.

Hines, M. 2011. Gender development and the human brain. Annual Review of Neuroscience, 34, 69-88.

Holtzman, N. S., Augustine, A. A., \& Senne, A. L. 2011. Are pro-social or socially aversive people more physically symmetrical? Symmetry in relation to over 200 personality variables. Journal of Research in Personality, 45, 687-691.

Honekopp, J., Manning, J. T., \& Muller, C. 2006. Digit ratio (2D:4D) and physical fitness in males and females: Evidence for effects of prenatal androgens on sexually selected traits. Hormones and Behavior, 49, 545-549.

Hromatko, I., Tadinac, M., \& Vranic, A. 2008. Femininity and masculinity across the menstrual cycle: A relation to mate value. Collegium Antropologicum, 32(Suppl. 1), 81-86.

Hughes, S. M., \& Gallup, G. G. 2003. Sex differences in morphological predictors of sexual behavior: Shoulder to hip and waist to hip ratios. Evolution and Human Behavior, 24, 173-178.

Jasienska, G., Lipson, S. F., Ellison, P. T., Thune, I., \& Ziomkiewicz, A. 2006. Symmetrical women have higher potential fertility. Evolution and Human Behavior, 27, 390-400.

Jensen-Campbell, L. A., Graziano, W. G., \& West, S. G. 1995. Dominance, prosocial orientation, and female preferences: Do nice guys really finish last? Journal of Personality and Social Psychology, 68, 427440.

Jokela, M., \& Keltikangas-Järvinen, L. 2009. Adolescent leadership and adulthood fertility: Revisiting the "central theoretical problem of human sociobiology". Journal of Personality, 77, 213-230.

Jokela, M., Kivimaki, M., Elovainio, M., \& Keltikangas-Jarvinen, L. 2009. Personality and having children: A two-way relationship. Journal of Personality and Social Psychology, 96, 218-230.

Johnstone, R. A., \& Manica, A. 2011. Evolution of personality differences in leadership. Proceedings of the National Academy of Sciences of the United States of America, 108, 8373-8378.

Kasperk, C. H., Wakley, G. K., Hierl, T., \& Ziegler, R. 1997. Gonadal and adrenal androgens are potent regulators of human bone cell metabolism in vitro. Journal of Bone and Mineral Research, 12, 464471.

Kearns, M. C., \& Calhoun, K. S. 2010. Sexual revictimization and interpersonal effectiveness. Violence and Victims, 25, 504-517.

Lukaszewski, A. W. 2013. Testing an adaptationist theory of trait covariation: Relative bargaining power as a common calibrator of an interpersonal syndrome. European Journal of Personality, 27, 328-345.

Lund, O. C. H., Tamnes, C. K., Moestue, C., Buss, D. M., \& Vollrath, M. 2007. Tactics of hierarchy negotiation. Journal of Research in Personality, 41, 25-44.

Lutchmaya, S., Baron-Cohen, S., Raggatt, P., Knickmeyer, R., \& Manning, J. T. 2004. 2nd to 4th digit ratios, fetal testosterone and estradiol. Early Human Development, 77, 23-28.

MacGreene, D., \& Navarro, R. L. 1998. Situation-specific assertiveness in the epidemiology of sexual victimization among university women. Psychology of Women Quarterly, 22, 589-604.

Manning, J. T. 2002. Digit ratio: A pointer to fertility, behavior, and health. New Brunswick, NJ: Rutgers 
University Press.

McCroskey, J. C. 1994. Introduction interpersonal communication. Edina, MN: Burgess International Group.

Michalski, R. L., \& Shackelford, T. K. 2010. Evolutionary personality psychology: Reconciling human nature and individual differences. Personality and Individual Differences, 48, 509-516.

Mikach, S. M., \& Bailey, J. M. 1999. What distinguishes women with unusually high numbers of sex partners? Evolution and Human Behavior, 20, 141-150.

Møller, A. P., \& Swaddle, J. P. 1997. Asymmetry, developmental stability, and evolution. Oxford, United Kingdom: Oxford University Press.

Nettle, D. 2005. An evolutionary approach to the extraversion continuum. Evolution and Human Behavior, 26, 363-373.

Nettle, D. 2006. The evolution of personality variation in humans and other animals. American Psychologist, 61, 622-631.

Penke, L., Denissen, J. J. A., \& Miller, G. F. 2007. The evolutionary genetics of personality. European Journal of Personality, 21, 549-587.

Puts, D. A., Welling, L. L. M., Burriss, R. P., \& Dawood, K. 2012. Men's masculinity and attractiveness predict their female partners' reported orgasm frequency and timing. Evolution and Human Behavior, 33, 1-9.

Putz, D. A., Gaulin, S. J. C., Sporter, R. J., \& McBurney, D. H. 2004. Sex hormones and finger length: What does 2D:4D indicate? Evolution and Human Behavior, 25, 182-199.

Rahman, Q., Korhonen, M., \& Aslam, A. 2005. Sexually dimorphic 2D:4D ratio, height, weight, and their relation to number of sexual partners. Personality and Individual Differences, 39, 83-92.

Reise, S. P., \& Wright, T. M. 1996. Personality traits, cluster B personality disorders, and sociosexuality. Journal of Research in Personality, 30, 128-136.

Rhodes, G., Simmons, L. W., \& Peters, M. 2005. Attractiveness and sexual behavior: Does attractiveness enhance mating success? Evolution and Human Behavior, 26, 186-201.

Richmond, V. P., \& McCroskey, J. C. 1990. Reliability and separation of factors on the assertivenessresponsiveness measure. Psychological Reports, 67, 449-450.

Richmond, V. P., \& McCroskey, J. C. 1992. Communication: Apprehension, avoidance, and effectiveness (3rd ed). Scottsdale, AZ: Gorsuch Scarisbrick.

Sakaguchi, K., Sakai, Y., Ueda, K., \& Hasegawa, T. 2007. Robust association between sociosexuality and self-monitoring in heterosexual and non-heterosexual Japanese. Personality and Individual Differences, 43, 815-825.

Singh, D., \& Singh, D. 2011. Shape and significance of feminine beauty: An evolutionary perspective. Sex Roles, 64, 723-731.

Swami, V., \& Tovee, M. J. 2005. Male physical attractiveness in Britain and Malaysia: A cross-cultural study. Body Image, 2, 383-393.

Testa, M., VanZile-Tamsen, C., \& Livingston, J. A. 2007. Prospective prediction of women's sexual victimization by intimate and nonintimate male perpetrators. Journal of Consulting and Clinical Psychology, 75, 52-60.

Thompson, C. A., Ishii, S., \& Klopf, D. 1990. Japanese and Americans compared on assertiveness/ responsiveness. Psychological Reports, 66, 829-830.

Thornhill, R., \& Gangestad, S. 1994. Human fluctuating asymmetry and sexual behavior. Psychological Science, 5, 297-302.

Tooby, J., \& Cosmides, L. 1992. The psychological foundations of culture. In J. H. Barkow, L. Cosmides, \& J. Tooby (Eds.), The adapted mind: Evolutionary psychology and the generation of culture (pp. 19136). New York, NY: Oxford University Press.

Trivers, R. 1972. Parental investment and sexual selection. In B. G. Campbell (Ed.), Sexual selection and the descent of man (pp. 136-179). Chicago, IL: Aldine.

Troutman, C. S., Burke, K. G., \& Beeler, J. D. 2000. The effects of self-efficacy, assertiveness, stress, and gender on intention to turnover in public accounting. Journal of Applied Business Research, 16, 63-74.

Twenge, J. M. 2001. Changes in women's assertiveness in response to status and roles: A cross-temporal meta-analysis, 1931-1993. Journal of Personality and Social Psychology, 81, 133-145.

Vallender, E. J., \& Lahn, B. T. 2004. Positive selection on the human genome. Human Molecular Genetics, 13(Suppl. 2), R245-R254. 
Walker, D. P., \& Messman-Moore, T. L. 2011. Number of sexual partners and sexual assertiveness predict sexual victimization: Do more partners equal more risk? Violence and Victims, 26, 774-787.

Welborn, T. A., Dhaliwal, S. S., \& Bennett, S. A. 2003. Waist-hip ratio is the dominant risk factor predicting cardiovascular death in Australia. The Medical Journal of Australia, 179, 580-585.

Wolf, M., \& McNamara, J. M. 2012. On the evolution of personalities via frequency-dependent selection. The American Naturalist, 179, 679-692.

Wolf, M., Van Doorn, G. S., \& Weissing, F. J. 2011. On the coevolution of social responsiveness and behavioural consistency. Proceedings of the Royal Society B: Biological Sciences, 278, 440-448.

Wright, T. M., \& Reise, S. P. 1997. Personality and unrestricted sexual behavior: Correlations of sociosexuality in Caucasian and Asian college students. Journal of Research in Personality, 31, 166-192.

Zaadstra, B. M., Seidell, J. C., Van Noord, P. A., te Velde, E. R., Habbema, J. D., Vrieswijk, B., \& Karbaat, J. 1993. Fat and female fecundity: Prospective study of effect of body fat distribution on conception rates. BMJ, 306, 484-487.

(Manuscript received 23 July, 2015; Revision accepted 1 November, 2016) 